\title{
Single strand annealing mathematical model for double strand break repair
}

\author{
Reza Taleei', Michael Weinfeld ${ }^{2}$ and Hooshang Nikjoo ${ }^{1 *}$
}

\begin{abstract}
Background: In this work we present, for the first time, a mechanistic mathematical model for single strand annealing (SSA) one of the three important double strand breaks (DSB) repair pathway. For this purpose, we predict the rate constants, which have not yet been measured experimentally, for the proteins involved in the repair. To maintain genome stability, DNA DSB are repaired by three main pathways, NHEJ (non-homologous end joining), HR (homologous recombination), and SSA. SSA is a compensating pathway for both HR and NHEJ. The three pathways are distinct in repair efficiency and fidelity. The SSA repair process is non-conservative which may cause genome translocation.

Methods: We employed a biochemical reaction rate model to investigate mechanistically the SSA repair pathway. The model resulted in a set of nonlinear differential equations which were solved numerically.

Results: The constant rates of the biochemical reactions were estimated by comparing the modelling results with chicken cell line (DT40), and mouse embryo fibroblast cell line (MEF) dose-equivalent unrepaired DSB (Deq) data after irradiation with 20 Gy X-rays. The model successfully predicted DSB repair of DT40 cell line irradiated with $80 \mathrm{~Gy}$ X-rays. The model was also employed to investigate dose rate effects on repair efficiency.

Conclusions: The model is capable of predicting repair efficiency of deficient cell lines (via mutation in specific enzyme). In the absence of quantitative data we present model predictions for protein reaction rate constants for Rad51 and Ku70 mutated DT40 and MEF cell lines. The present work is part of the development of a complete model of DNA DSB repair, including HR and NHEJ. A comprehensive model of DNA repair is needed in development of new ideas in radiation cancer therapy, and risk assessment in human from exposures to low doses of ionizing radiations.
\end{abstract}

\section{Background}

lonizing radiation induce a plethora of DNA damage including single strand breaks (SSB), double-strand breaks (DSB), and chemically induced base and strand lesions [1]. DSB is considered to be the critical damage to be repaired. DSB can be divided into two main types of complex, and simple lesions $[2,3]$. Complex DSB are defined as more than one DSB, or a DSB accompanied with base lesions or SSB within one turn of the helix [3]. The complexity of the DSB lesions has been shown to increases with the LET of radiation [4]. It has been hypothesised that more complex DSBs are more difficult to repair [5]. Alternative to DSB complexity have also been put forward in terms of chromatin unravelling [6]. Error prone or nonconservative repair pathways together with unrepaired DSB may lead to cell death, genomic instability, mutation, or oncogenic transformation $[7,8]$. There are at least three competitive pathways for the repair of DSB. Non-homologous end joining (NHEJ), the main repair pathway in higher eukaryotes, is an error prone pathway $[9,10]$. Conservative homologous recombination (HR) $[11,12]$, and nonconservative single strand annealing (SSA) pathway $[11,13]$ are considered as the two remaining pathways of DSB repair. NHEJ simply rejoins the DSB ends directly, while HR requires the intact homologous non-sister chromatid to start the repair. On the other hand SSA utilizes direct repeat sequences for its repair process. Almost

*correspondence: hooshang.nikjoo@ki.se

${ }^{1}$ Radiation Biophysics Group, Department of Oncology-

Pathology, Karolinska Institutet, Stockholm, Sweden.

Full list of Author's information is available at the end of the article half of the human genome consists of repetitive DNA sequences [14], making SSA a potentially competitive pathway for human DNA DSB repair. The main proteins involved in NHEJ and HR repair pathways are distinct. Ku70, Ku80, DNA-dependent protein kinase catalytic subunit (DNA-PKcs), XLF, X-ray repair cross complementing group 4 (XRCC 4) and ligase IV are the main up to date identified proteins involve in NHEJ repair, while Mre11-Rad50-Nbs1 (MRN), Replication Protein A (RPA), Rad51, Rad52, and Rad54 are the main proteins involved in HR. Mutation in the main proteins involved in the HR and NHEJ pathways is assumed to promote SSA repair pathway. Recently a poly (ADP-ribose) polymerase (PARP-1) dependent or backup NHEJ pathway has been proposed to be active when DNA-PK dependent NHEJ pathway is mutated $[15,16]$. The main proteins involved in this pathway are poly (ADP-ribose) polymerase-1 (PARP-1) and ligase III (lig III). Although the backup NHEJ is considered to be cell cycle dependent, the characteristics and functions of the proteins active in the backup NHEJ pathway have not yet been well identified to be considered for mathematical model. In a recent model of HR repair pathway [17] the initial steps starts with resecting the DSB with MRN complex proteins in mammals $[18,19]$. The processed ssDNA is coated by replication protein A (RPA) which has a strong affinity for ssDNA and removes other structures bound to DNA [20]. The phosphorylation of RPA allows Rad52 to bind efficiently with RPA-ssDNA complex [17,21,22]. Rad52-RPA-ssDNA complex further processes the damage by either Rad51-mediated HR, or Rad51independent SSA repair [20]. Ercc1/XPF endonuclease in vertebrates $[23,24]$ removes the non-homologous $3^{\prime}$-ends. The Final step of SSA is the ligation which is probably accomplished by ligase III [25].

(C) 2012 Nikjoo et al; licensee Herbert Publications Ltd. This is an Open Access article distributed under the terms of Creative Commons Attribution License (http://creativecommons.org/licenses/by/3.0). This permits unrestricted use, distribution, and reproduction in any medium, provided the original work is properly cited. 
Taleei et al. Journal of Molecular Engineering \& Systems Biology 2012, http://www.hoajonline.com/journals/pdf/2050-1412-1-1.pdf

Recent radiation biology experiments have well contributed to the understanding of the mechanism of DSB repair, however some important details remain unrevealed [15]. Mathematical modelling in biology has played a promising role in predicting the biological mechanisms and further suggesting experiments for the unknown processes. Due to the availability of kinetic data, substantial mathematical models have been proposed for cell cycle kinetic modelling $[26,27]$. In the recent a number of papers have been published on modelling base excision repair (BER) using kinetic modelling [28,29], modelling of DSB rejoining [30-35], and more specifically a kinetic model of NHEJ [36]. But, there is still lack of mathematical models for other repair pathways, and a comprehensive model of DNA DSB repair. A complete mathematical model of DSB repair requires modelling of each pathway separately, and combining the models taking into account the cell cycle dependent contribution and hierarchy of the repair pathways [37]. In this work, we present a biochemical kinetic model describing a new model for SSA repair pathway. In this model we have predicted the rate constants of the proteins activity in the repair.

\section{Materials}

Deng and colleagues have published an experimental model for the initial steps of HR repair [17]. Figure 1 presents a schematic diagram of the steps involved in the SSA repair pathway. The model relies on prominent experimental finding for a complete SSA repair process $[20,38,39]$. In this section we propose a biochemical kinetic model to describe the DSB repair by SSA pathway.
A y1
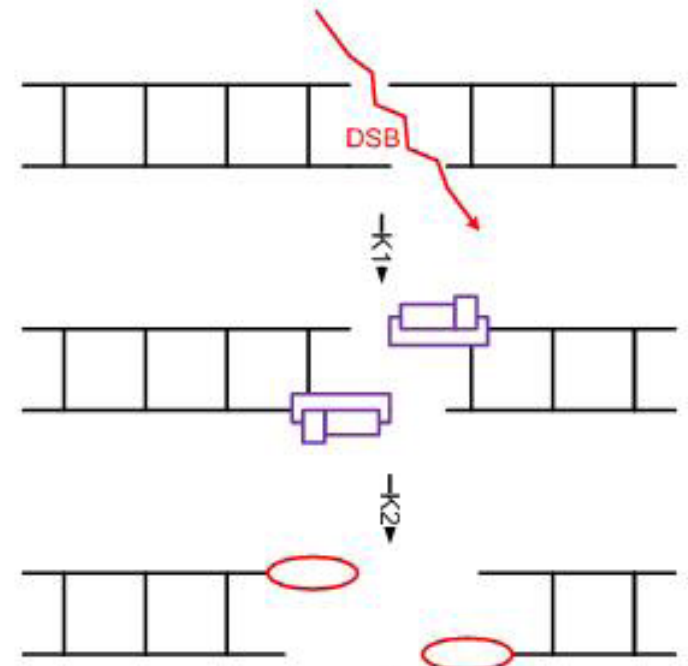

交

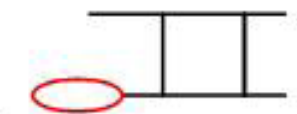

$\underset{⿱}{\mathbb{W}}$

y4
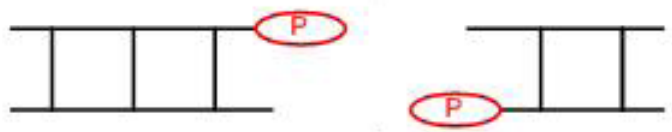

衣

y5
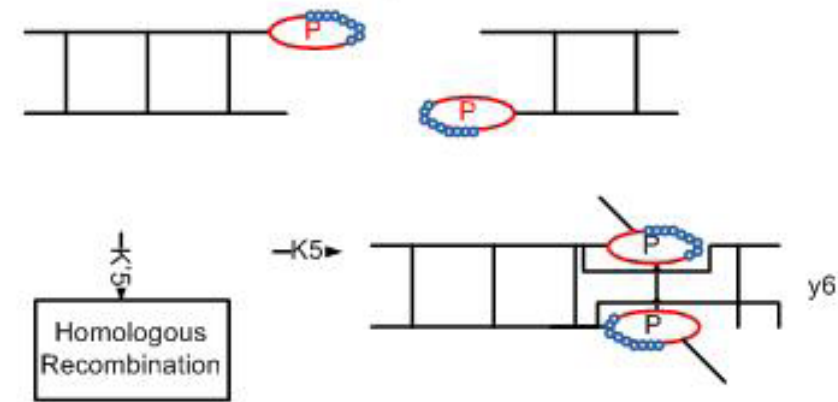

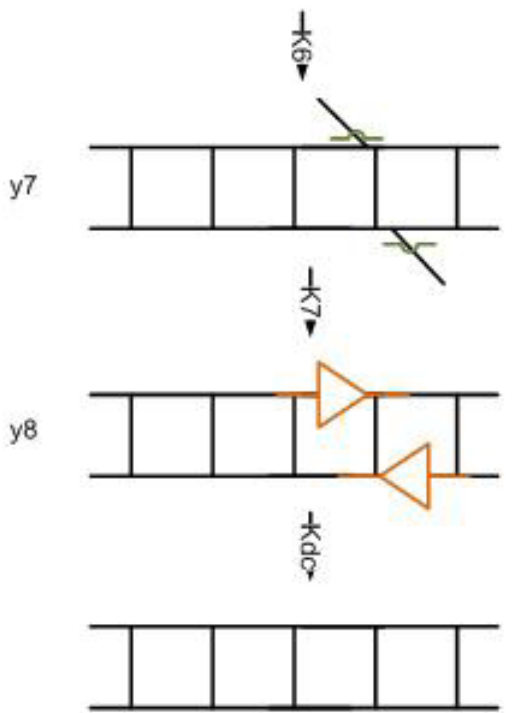

MRN

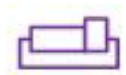

RPA

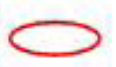

P-RPA

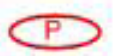

Rad52

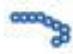

Ercc1/Xpf

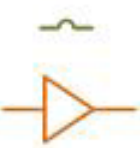

Figure. 1 Schematic model of DSB repair processed by HR and SSA repair pathways. After the DSB is induced by radiation, the HR and SSA repair pathways start the repair process with MRN, RPA, Phosphorylated-RPA (P-RPA), and Rad52 proteins (Common starting steps is panel A and panel B). The repair process continues with either panel A) Rad54 mutated cell line, or panel B) Rad51 mutated cell line using Ercc1/ Xpf and ligase III proteins. 
The mass action law has been used to derive the kinetic equations according to the model illustrated in Figure 1. The nomenclature $\mathrm{Y}_{i}, \mathrm{~V}_{\mathrm{i}}$, and $\mathrm{K}_{\mathrm{i}}$ stand for the repair complex, repair rate, and repair rate constant for $\mathrm{i}=1$ to 8 , respectively. As it is illustrated in Figure 1 a there are 8 biochemical repair process on the DSB. The proteins bind to the DSB to form the repair complex. The rate of DSB induction $\left(\frac{d Y_{1}}{d t}\right)$ is linearly related to the dose rate, with the DSB induction-rate per unit dose constant (a).

$$
V_{1}=K_{1}[M R N] Y_{1}
$$

When double-strand break is induced, MRN complex resects it to form ssDNA tails. The concentrations of the proteins (e.g. MRN) are shown with brackets in the equations. RPA binds very strongly to ssDNA and removes any secondary structure.

$$
\frac{d Y_{2}}{d t}=V_{1}-V_{2}
$$

Where $V_{2}=K_{2}[R P A] Y_{2}$ $\frac{d Y_{1}}{d t}=\alpha \frac{d D}{d t}-V_{1}$

Where

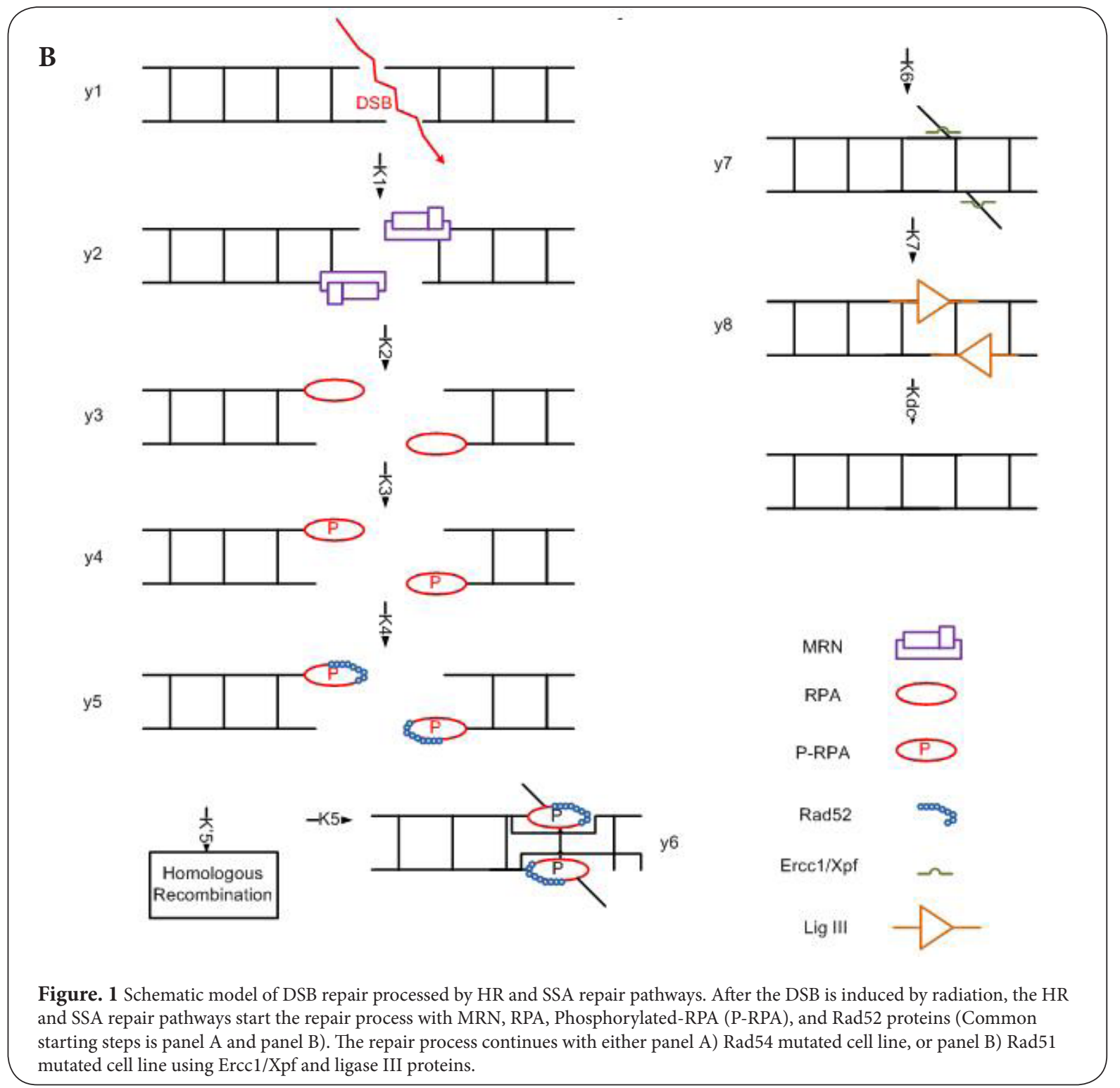


The binding affinity of RPA to $5^{\prime}$ and $3^{\prime}$ ssDNA increases when it binds to Rad52, which will consequently inhibit Rad52-mediated DSB repair. On the other hand protein-protein interaction of phosphorylated RPA (P-RPA) and monomeric Rad52 increases the affinity of Rad52 to bind ssDNA and process the DSB repair. Therefore RPA should phosphorylate before Rad52 binds to it.

$$
\frac{d Y_{3}}{d t}=V_{2}-V_{3}
$$

Where

$$
V_{3}=K_{3} Y_{3}
$$

After Rad52 binds to P-RPA, it is able to proceed with the repair process by annealing the strand ends.

$\frac{d Y_{4}}{d t}=V_{3}-V_{4}$

Where

$$
V_{4}=K_{4}[\operatorname{Rad} 52 \& P-R P A] Y_{4}
$$

Rad51 plays an important role to mediate a HR pathway and prevent Rad52 to pursue a Rad51-independent SSA repair pathway [37]. As shown in Figure 1, the SSA pathway could successfully anneal the DSB by Rad52 annealing process. Direct repeat sequence is necessary for this approach.

$\frac{d Y_{5}}{d t}=V_{4}-V_{5}-V_{6}$

Where

$$
\begin{aligned}
& V_{5}=K_{5}\left[\operatorname{Rad} 52 \& P_{-} R P A\right] Y_{5} \\
& V_{6}=K^{\prime}{ }_{5} Y_{5}
\end{aligned}
$$

As it has been shown that Rad52 has a second order rate activity [40], equation ( $8^{\prime}$ ) could be proposed instead of equation (8).

$$
V_{4}=K_{4}\left[R a d 52 \& P_{-} R P A\right] Y_{4}^{2}
$$

In the case of Rad51-mutant cells one can reduce the equations with removing equation (9), while equation 10' replaces equation 10. The model for Rad51-mutant cells is shown in Figure 1B. In this case, Rad51 does not inhibit Rad52 annealing process.

$$
V_{5}=K_{5}\left[\operatorname{Rad} 52 \& P_{-} R P A\right] Y_{5}
$$

Ercc1/Xpf endonuclease in vertebrates interacts functionally with Rad52 to remove the $3^{\prime}$-overhangs. $\frac{d Y_{6}}{d t}=V_{5}-V_{7}$

Where

$V_{7}=K_{6}[\operatorname{Erccl} / X p f] Y_{6}$

Finally gap filling and ligation will end the SSA repair process. Ligase III is proposed to be the only candidate for this process.

$\frac{d Y_{7}}{d t}=V_{7}-V_{8}$

Where

$V_{8}=K_{7}[\operatorname{LigIII}] Y_{7}$

The repair process finishes, when all the enzymes successfully precede the sequential repair process. $\mathrm{K}_{\mathrm{dc}}$ is the rate constant for the ligation of the nick and the end of the repair process.

$\frac{d Y_{8}}{d t}=V_{8}-V_{9}$

Where

$V_{9}=K_{d c} Y_{8}$

To simplify the modelling equations we introduce scaling factors similarly to previous works [36]. The scaling factor $C$ which is the sum of repair proteins $\left(E_{i}\right)$ and repair complex concentrations $\left(Y_{i}\right)$ is considered to be constant and equal to 3000 .

$C=E_{i}+\sum_{j=i}^{8} Y_{i}=c t e$

$y_{i}=\frac{Y_{i}}{C}$

$k_{i}=C K_{i}$

$c_{i}=\frac{\sum_{j=i}^{8} y_{i}}{C}$

The following equations are derived considering the scaling factor $\mathrm{C}$ and substituting the new parameters in the complete set of the kinetic equations of the SSA model.

$\frac{d y_{1}}{d t}=\frac{\alpha}{C} \frac{d D}{d t}-v_{1}$ 


$$
\begin{aligned}
& \frac{d y_{2}}{d t}=v_{1}-v_{2} \\
& \frac{d y_{3}}{d t}=v_{2}-v_{3} \\
& \frac{d y_{4}}{d t}=v_{3}-v_{4} \\
& \frac{d y_{5}}{d t}=v_{4}-v_{5}-v_{6} \\
& \frac{d y_{7}}{d t}=v_{7}-v_{8} \\
& \frac{d y_{8}}{d t}=v_{8}-v_{9} \\
& \frac{d y_{6}}{d t}=v_{5}-v_{7}
\end{aligned}
$$

Where

$$
\begin{aligned}
& v_{1}=k_{1}\left(1-c_{2}\right) y_{1} \\
& v_{2}=k_{2}\left(1-c_{3}\right) y_{2} \\
& v_{3}=K_{3} y_{3} \\
& v_{4}=k_{4}\left(1-c_{5}\right) y_{4} \\
& v_{5}=k_{5}\left(1-c_{6}\right) y_{5} \\
& v_{6}=K_{5}^{\prime} y_{5} \\
& v_{7}=k_{6}\left(1-c_{7}\right) y_{6} \\
& v_{8}=k_{7}\left(1-c_{8}\right) y_{7} \\
& v_{9}=K_{d c} y_{8}
\end{aligned}
$$

If the cells are mutated in Rad51 instead of Rad54, equations (39) to (41) replace the equations (26) to (29). The first (22) to (25) equations remain the same, as the beginning of the repair process is independent of Rad51 or Rad54 mutation (Figure 1 panel B).

$$
\begin{aligned}
& \frac{d y_{5}}{d t}=v_{4}-v_{5} \\
& \frac{d y_{6}}{d t}=v_{5}-v_{6} \\
& \frac{d y_{7}}{d t}=v_{6}-v_{7}
\end{aligned}
$$

Where

$$
\begin{aligned}
& v_{4}=k_{4}\left(1-c_{5}\right) y_{4} \\
& v_{5}=k_{5}\left(1-c_{6}\right) y_{5} \\
& v_{6}=k_{6}\left(1-c_{7}\right) y_{6} \\
& v_{7}=K_{d c} y_{7}
\end{aligned}
$$

\section{Results and Discussion}

The kinetic model developed in this work consists of eight nonlinear ordinary differential equations. The complete set of equations is proposed for Ku70 and Rad54-mutated chicken B cell line (DT40) and mouse embryo fibroblast cell line (MEF). Ku70 and Rad54 mutation makes SSA annealing the prevalent repair mechanism. Ligase IV, KU70 and Rad51 mutation is an alternative way to make SSA the prevalent mechanism [37]. In this case the number of equations will indeed reduce to seven, since Rad51 doesn't inhibit the Rad52-mediated annealing pathway. There is lack of experimental data in the literature for SSA pathway with Rad51 mutated cell lines, because the Rad51-mutant cell lines are lethal [41]. The first estimate of the rate constants listed in Table 1 were made by considering published data such as fast action of RPA on ssDNA, the increased efficiency of Rad52 for SSA when combined to P-RPA [42], and finally fast resection action of MRN even in G1 cell cycle phase [39], even though homologous repair is not so active. The final rate estimation involves carefully examining the effect of changing each rate constant on the repair complex kinetics, and considering the fact that sum of the scaled complexes $y 1$ to $y 8$ is equal to the unrepaired DSB for each time (X-value). Therefore, the rate constants values listed in Table 1 were determined by comparing model results with experimental data for DT40 and MEF cells, irradiated with 20 Gy of X-ray dose. The rate constants were then verified by comparing the model solutions with the experimental data for DT40 and MEF cells for higher and lower doses of $10 \mathrm{~Gy}$ and $80 \mathrm{~Gy}$. Currently, there are no experimental data to validate the predicted rate constants.

\begin{tabular}{ccc}
\hline Rate constants & DT40 cells & MEF cells \\
\hline $\mathrm{k}_{1}\left(\mathrm{~h}^{-1}\right)$ & 40 & 45 \\
$\mathrm{k}_{2}\left(\mathrm{~h}^{-1}\right)$ & 15 & 15 \\
$\mathrm{~K}_{3}\left(\mathrm{~h}^{-1}\right)$ & 5 & 15 \\
$\mathrm{k}_{4}\left(\mathrm{~h}^{-1}\right)$ & 5 & 10 \\
$\mathrm{k}_{5}\left(\mathrm{~h}^{-1}\right)$ & 100 & 50 \\
$\mathrm{~K}_{5}^{\prime}\left(\mathrm{h}^{-1}\right)$ & 40 & 40 \\
$\mathrm{k}_{6}\left(\mathrm{~h}^{-1}\right)$ & 0.5 & 4 \\
$\mathrm{k}_{7}\left(\mathrm{~h}^{-1}\right)$ & 0.08 & 0.5 \\
$\mathrm{~K}_{\mathrm{dc}}\left(\mathrm{h}^{-1}\right)$ & 0.5 & 0.15 \\
\hline
\end{tabular}

Table. 1 Chicken B (DT40) and mouse embryo fibroblast (MEF) cell lines rate constants. 
Taleei et al. Journal of Molecular Engineering \& Systems Biology 2012, http://www.hoajonline.com/journals/pdf/2050-1412-1-1.pdf

Figure 2 illustrates the comparison of SSA kinetic model with experimental data for DT40 [43] and MEF cell lines [44] irradiated with 20 Gy. FAR (Fraction of Activity released) or Deq (dose equivalent unrepaired DSB or the respective radiation dose without repair) are determined experimentally by pulse-field gel electrophoresis (PGFE) after incubation. PFGE uses electric field to separate DNA fragments that makes it possible to measure the fraction of total DNA release. FAR is associated with relatively large fragment sizes, which makes the method sensitive to relatively large doses ( $>10$ Gy). In order to convert FAR to Deq, dose response curves are used. For total dose of less than $20 \mathrm{~Gy}$ the dose response curve is almost linear. The Deq or FAR that are the measure of remaining (not repaired) DSBs were considered for comparing the modelling and experimental results. Therefore, Sum of the scaled repair complexes y1 to y8 (mathematically presenting unrepaired DSB) are equivalent to the FAR expressed in Deq. The modelling and experimental Deq results show fast and slow repair fractions which are in agreement with the studies indicating SSA partly compensates for both HR and NHEJ pathways, when the cells are mutated in Rad54, and Ku70 or ligase IV [37,45-47]. It is noticeable that MEF repairs DSB more efficiently comparing to DT40. The repairing results consist of fast and slow repair components. The fast fraction of repair in MEF cell lines is shorter and more effective. The characteristics of the repair fractions of both cell lines will be discussed in more detail.

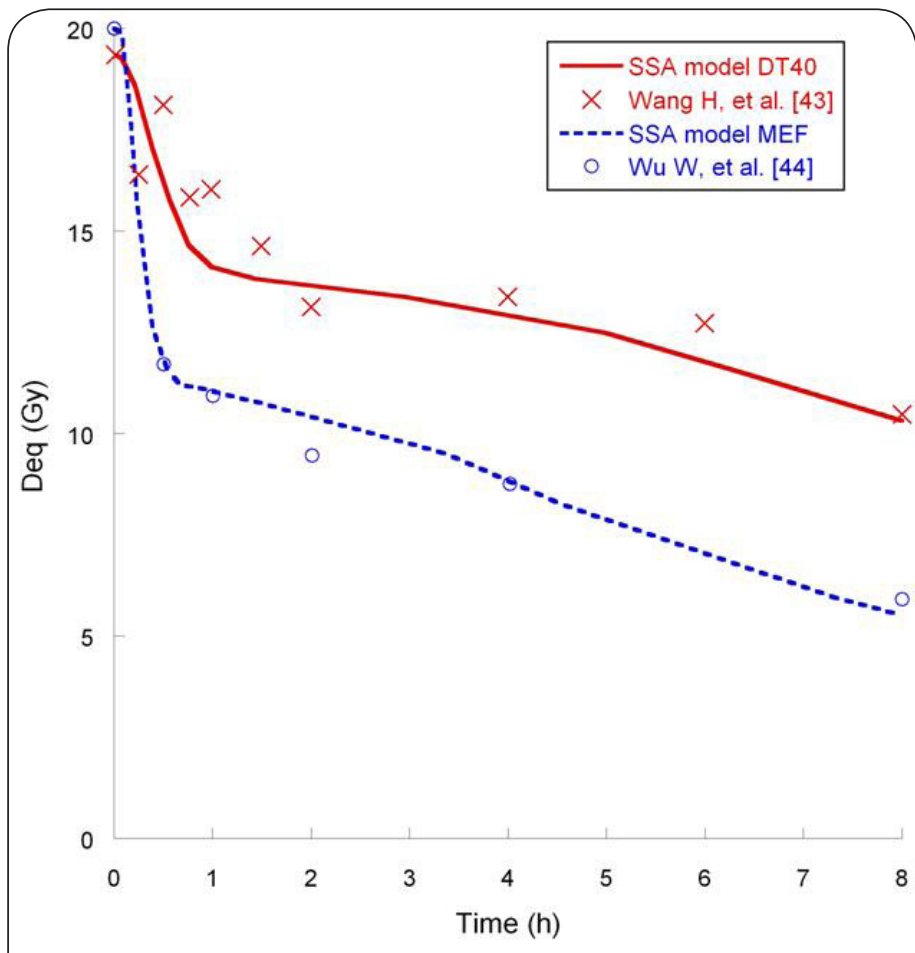

Figure. 2 Comparison of SSA model calculations with dose equivalent unrepaired (Deq) DSB for MEF (mouse embryo fibroblast) [44] and DT40 (chicken B) [43] cells irradiated with 20 Gy X-rays.
In order to benchmark the rate constants listed in Table 1, the experimental result of MEF and DT40 cell lines irradiated with $\mathrm{X}$-ray dose of $10 \mathrm{~Gy}$ and $80 \mathrm{~Gy}$ respectively have been considered. The SSA model result is in accordance with the experimental data illustrated in Figure 3. Second order kinetic rate constant for Rad52 doesn't make a noticeable difference in the model results for both 80 and 10 Gy X-rays (results not shown). After eight hours about $45 \%$ of the DSBs are repaired for both 80 and 20 Gy X-rays for DT40 cell line. The repair in MEF cell line is more efficient, about $70 \%$ of the DSBs are repaired for both 20 and $10 \mathrm{~Gy}$ after 8 hours. The fast fraction of repair is about $0.6 \mathrm{~h}$ and $1 \mathrm{~h}$ for DT40 and MEF cell lines, respectively. About $30 \%$ and $45 \%$ of the DSB are repaired in the fast fraction of repair in DT40 and MEF cell lines respectively.

For calculating fast and slow components of DSB rejoining, twoexponential approximation equations representing the slow and fast components of the repair curve Deq(or FAR) $=\mathrm{Ae}^{-\mathrm{bt}}+\mathrm{Ce}^{-\mathrm{dt}}$ were used [48]. The half-times and fractions of slow and fast components of repair are given by $t_{50, \text { slow }}=\ln 2 / d, t_{50 \text {,fast }}=\ln 2 / b, F_{\text {slow }}=C /(A+C)$, and $F_{\text {fast }}=A /(A+C)$, respectively. The parameters $A, C, b$, and $d$ were derived from the two-exponential fit to both experimental and model results. The half time of fast and slow repair for 10, 20 and 80 Gy exposures for both cell lines are listed in Table 2. The fast and slow half time of the SSA calculations are in agreement with the experimental results for DT40 and MEF cell lines.

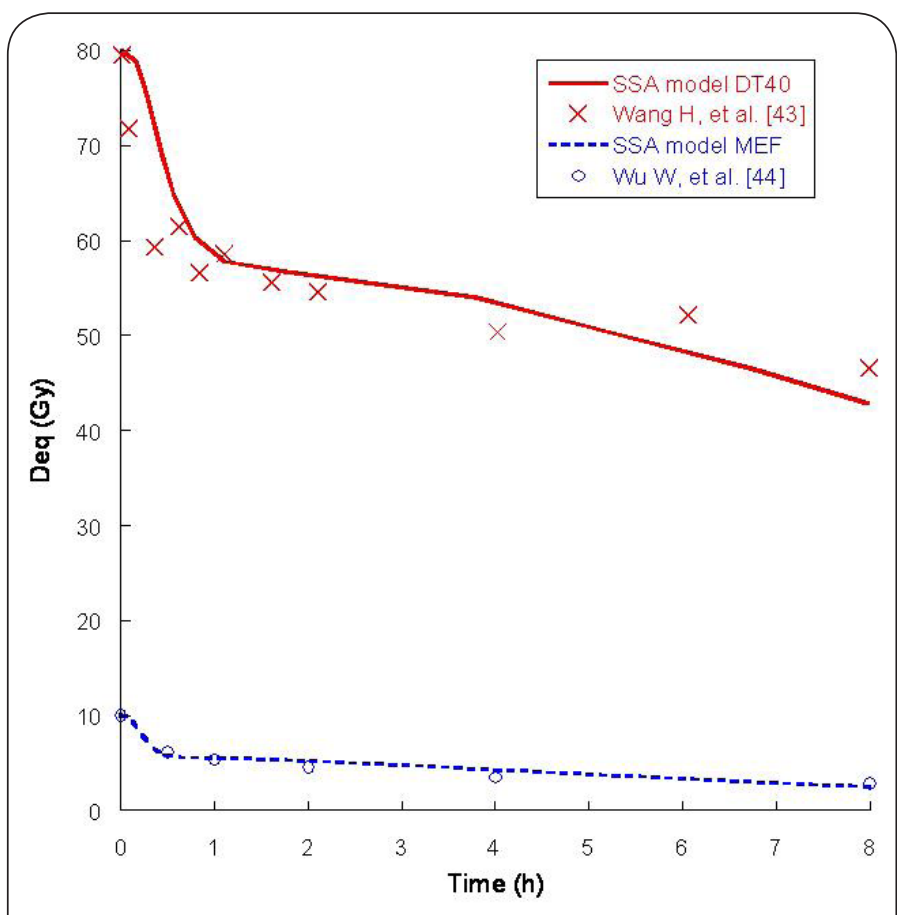

Figure. 3 Comparison of SSA model calculations with dose equivalent unrepaired (Deq) DSB for (mouse embryo fibroblast) MEF [44] and DT40 (chicken B) [43] cells irradiated with $10 \mathrm{~Gy}$ and $80 \mathrm{~Gy} \mathrm{X}$-rays, respectively. 
Table 3 provides the fraction of fast and slow repair for 10,20 and 80 Gy doses calculated with the two exponential approximations for both cell lines. The SSA model calculations show similar fractions of fast and slow repair to experimental results of DT40 and MEF cell lines. The fast fraction of repair is less than the slow fraction for both cell lines for all doses. The slow fraction of repair is about $72.5 \%$ and $55 \%$ for DT40 and MEF cell lines, respectively, showing more involvement of the fast fraction of MEF cell line on the repair of damage.

Figure 4 illustrates FAR for DT40 and MEF cell lines irradiated with $600,60,6$, and $0.6 \mathrm{~Gy} / \mathrm{h}$ dose rates versus the accumulated dose. The initial number of DSBs increases linearly with dose. The repair effect tends to decrease the number of DSBs, and consequently the FAR which is the measure of the non-repaired DSB. The high dose rate effect is clearly noticeable in both cell lines. Repair efficiency decreases with increase of dose rate. DT40 cell line shows less repair efficiency comparing to MEF cell line. There is almost no difference between the initial damage induced and two dose rates 600 , and $60 \mathrm{~Gy} / \mathrm{h}$ for DT40. In contrast MEF cell line irradiated with $60 \mathrm{~Gy} / \mathrm{h}$ dose rate shows more repair efficiency at cumulative doses higher than 40 Gy as seen in Figure 4 panel B. The results is reasonable as MEF cell line show more fast fraction of repair and more efficiency of repair in comparison with DT40 cell line.

The repair efficiency of SSA pathway could rise, if the cells were mutated in Rad51 instead of Rad54. This approach reduces the equations to seven as explained in material and methods. Table 4 lists the rate constants used for the DT40 cells mutated in Ku70 and Rad51. The first three reaction rates which represent MRN, RPA, and Rad52 processes are not changed as the repair process is the same for the first 3 proteins for both Rad51 and Rad54 mutated cells.

Table. 2 Comparison of the half time of the slow and fast components of the repair process results from SSA model calculations with MEF [41] and DT40 [40] cells irradiated with 10, 20, and 80 Gy X-rays.

\begin{tabular}{ccccccccc}
\multicolumn{4}{c}{} & \multicolumn{4}{c}{ MEF Cell Line } & \multicolumn{3}{c}{ DT40 Cell Line } \\
\hline & Half Time $(\mathbf{h})$ for 20 Gy & \multicolumn{2}{c}{ Half Time $(\mathbf{h})$ for 10 Gy } & Half Time (h) for 20 Gy & \multicolumn{2}{c}{ Half Time (h) for 80 Gy } \\
\hline Fast & Kinetic Model & Wu et al. & Kinetic Model & Wu et al. & Kinetic Model & Wang et al. & Kinetic Model & Wang et al. \\
Slow & 0.19 & 0.13 & 0.17 & 0.24 & 0.33 & 0.54 & 0.35 & 0.22 \\
\hline
\end{tabular}

Table. 3 Comparison of the repair fraction of the slow and fast components of the repair process results from SSA model calculations with MEF [41] and DT40 [40] cells irradiated with 10, 20, and 80 Gy X-rays.

MEF Cell Line DT40 Cell Line

\begin{tabular}{ccccccccc}
\hline & \multicolumn{2}{c}{ Repair Fraction (\%) for 20 Gy } & \multicolumn{2}{c}{ Repair Fraction (\%) for 80 Gy } & \multicolumn{2}{c}{ Repair Fraction (\%) for 20 Gy } & \multicolumn{2}{c}{ Repair Fraction (\%) for 80 Gy } \\
\hline & Kinetic Model & Wu et al. & Kinetic Model & Wu et al. & Kinetic Model & Wang et al. & Kinetic Model & Wang et al. \\
\hline Fast & 46 & 41.9 & 45 & 46.5 & 28.2 & 21.5 & 28.8 & 24 \\
Slow & 54 & 58.1 & 55 & 53.5 & 71.8 & 78.5 & 71.2 & 67 \\
\hline
\end{tabular}
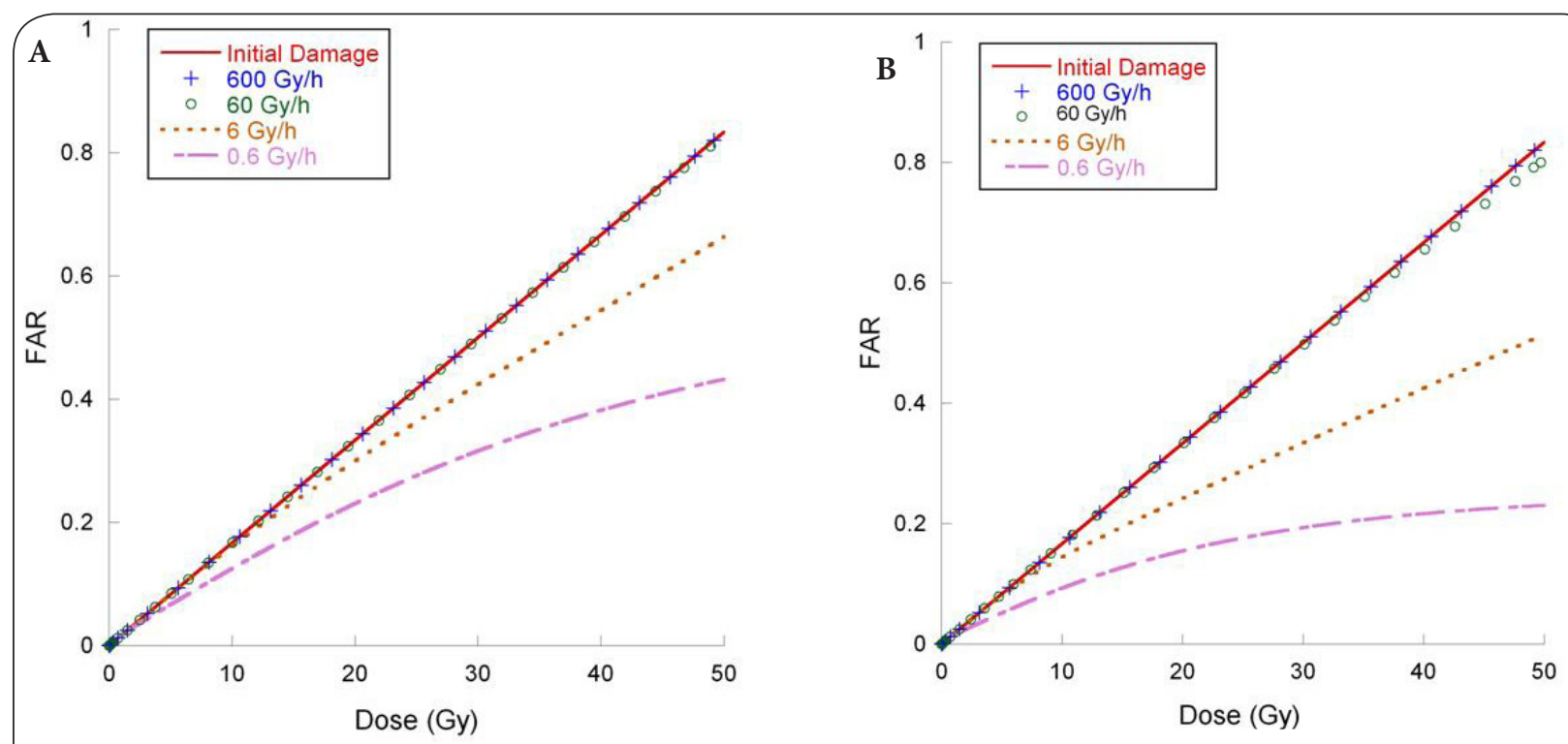

Figure. 4 Fraction of activity released for $600,60,6,0.6 \mathrm{~Gy} / \mathrm{h}$ dose rates, plotted against the cumulative dose for panel A) DT40 (chicken B) and panel B) MEF (mouse embryo fibroblast). 
Taleei et al. Journal of Molecular Engineering \& Systems Biology 2012,

http://www.hoajonline.com/journals/pdf/2050-1412-1-1.pdf

Figure 5 provides the SSA kinetic model prediction for $K u 70$ and Rad51 mutated cell. There are no experimental data available to benchmark the results. As foreseen, the model predicts an efficient activity for SSA pathway for DT40 cell line especially in the late repair part compensating more for HR Rad51-dependent pathway. The efficiency of the repair increases from about $40 \%$ to about $70 \%$ after 8 hours.

\section{Conclusions}

We have developed a new SSA kinetic rate model to investigate the repair efficiency of this pathway. The model is based on experimental deductions on the mechanism of DSB repair which we expressed them as a set of nonlinear equations using the mass action law. In order to be able to numerically solve the equations, we have predicted the rate constants of the proteins involved in DSB repair in the absence of quantitative experimental data. In the absence of human data, the model was benchmarked with chicken B (DT40) and mouse embryo fibroblast (MEF) cell lines irradiated with doses ranging from 10Gy to $80 \mathrm{~Gy}$. The available experimental methods to investigate the kinetics of DSB repair such as $\mathrm{Y}-\mathrm{H} 2 \mathrm{AX}$ foci kinetics are not a tempo-spatial sensitive method to be used for benchmarking the repair models. Similarly, pulsed-field-gel-electrophoresis (PFGE) is not also suitable as the method is insensitive to low dose irradiation. The limitations in experimental methods have impeded the development of accurate mechanistic models for DNA repair. Another problem emerging from experimental data is that the targeted protein is not always fully mutated. While in modelling we assume fully mutated gene. However, mathematical methods for DSB repair could overcome some of the experimental limitations, such as low dose problems and quantification of the rate constants. The repair models can be applied to test the efficiency of repair of DSBs in simulated damage using Monte Carlo track structure methods. In order to be able to

Table 4 Chicken B (DT40) Rad51 and Ku70- mutated cell lines reaction rates.

\begin{tabular}{cc}
\hline Rate constants & DT40 cells \\
\hline k1 (h-1) & 40 \\
k2 (h-1) & 15 \\
K3 (h-1) & 5 \\
k4 (h-1) & 100 \\
k5 (h-1) & 30 \\
k6 (h-1) & 0.2 \\
Kdc (h-1) & 0.7 \\
\hline
\end{tabular}

investigate the SSA model we have studied the HR and NHEJ repair mutated cells. We pose two questions to examine the validity of the model: a) is SSA the main repair pathway for DSB when repair factors like Rad54 and Ku70 are mutated? and b) how accurate can we predict the rate constants? In answer to the first question, there are two possible hypotheses. The first scenario is that SSA can partly compensate for deficient HR and NHEJ repair pathways, while in the second scenario we argue that backup NHEJ is a competitive repair pathway. Our work confirms the first scenario could potentially be the main repair pathway to repair the DSB in the absence of NHEJ and HR. However, the second scenario could still be valid, because one of the main proteins active in the backup NHEJ (ligase III) is involved in the SSA model. This means the backup NHEJ and SSA repair pathways cooperate to repair the DSB in the absence of NHEJ and HR. The model has the scope to be improved by considering the complete backup NHEJ pathway when all proteins involved in repair are identified. In the second question, we asked how accurate can we predict the rate constants? Currently, there are no protein rate constants available in the literature. The reaction rates listed in Tables 1 and 4 were estimated for the repair action of enzymes for MEF and DT40 cell lines. The reaction rates were confirmed with 10Gy and 80Gy X-ray doses for both cell lines. In addition, the model is capable of predicting repair efficiency of Rad51 deficient cell lines. The SSA model presented in this work is part of a comprehensive DSB repair model being developed. The complete model requires incorporating the other important repair pathways (NHEJ and HR), and factors such as mutual activation, inhibition of enzymes, and cell cycle.

\section{Acknowledgements}

The work was supported by SSM the Swedish Radiation Safety Authority, and Karolinska Institutet.

\section{Competing interests}

The Authors declare that they have no competing interests.

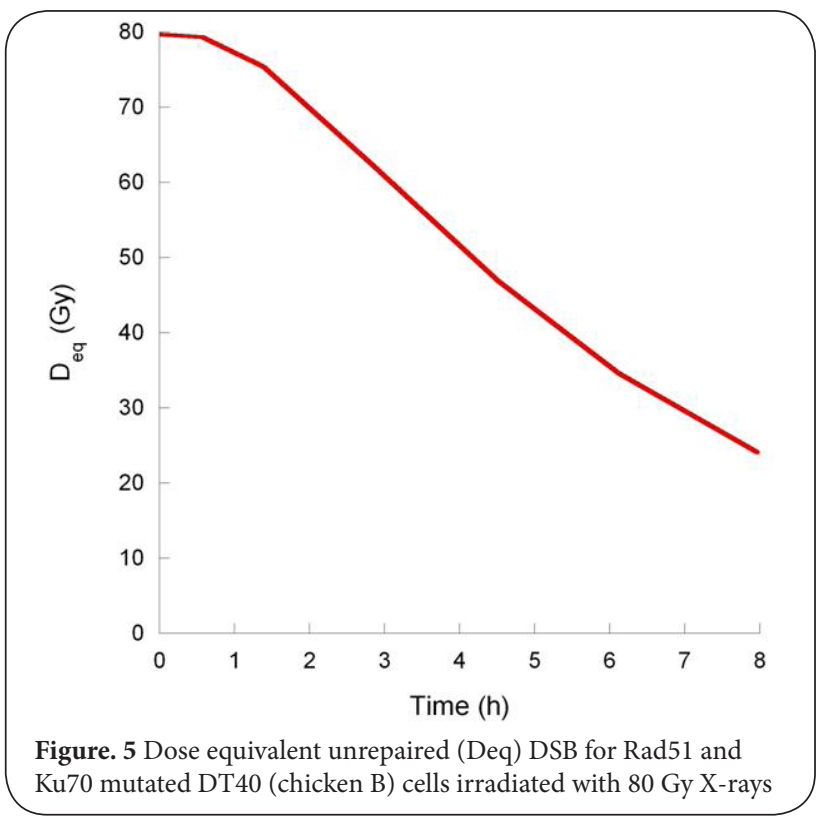




\section{Author's information}

${ }^{2}$ Cross Cancer Institute, 11560 University Avenue, Edmonton AB T6G 1Z2, Canada.

\section{Article history}

Editor: Hiroki Yokota, Indiana University, USA.

Received: 30-Jan-2012 Revised: 04-Feb-2012

Accepted: 12-Feb-2012 Published: 16-Apr-2012

\section{References}

1. Ward JF: Biochemistry of DNA lesions. Radiat Res Suppl 1985; 8;S10311. | Pubmed

2. Charlton DE, Nikjoo H, Humm JL: Calculation of initial yields of singleand double-strand breaks in cell nuclei from electrons, protons and alpha particles. Int J Radiat Biol 1989; 56;(1.);1-19. I Pubmed

3. Nikjoo H, O'Neill P, Goodhead DT, Terrissol M: Computational modelling of low-energy electron-induced DNA damage by early physical and chemical events. Int J Radiat Biol 1997; 71;(5.);467-83. | Pubmed

4. Nikjoo H, O'Neill P, Wilson WE, Goodhead DT: Computational approach for determining the spectrum of DNA damage induced by ionizing radiation. Radiat Res 2001; 156;(5 Pt 2.);577-83. | Pubmed

5. Weinfeld M, Rasouli-Nia A, Chaudhry MA, Britten RA: Response of base excision repair enzymes to complex DNA lesions. Radiat Res 2001; 156;(5 Pt 2.);584-9. | Pubmed

6. Goodarzi AA, Noon AT, Jeggo PA: The impact of heterochromatin on DSB repair. Biochem Soc Trans 2009; 37;(Pt 3.);569-76. | Pubmed

7. Sankaranarayanan $\mathrm{K}$, Wassom JS: lonizing radiation and genetic risks XIV. Potential research directions in the post-genome era based on knowledge of repair of radiation-induced DNA double-strand breaks in mammalian somatic cells and the origin of deletions associated with human genomic disorders. Mutat Res 2005; 578;(1-2.);333-70. | Article I Pubmed

8. Wallace SS: Biological consequences of free radical-damaged DNA bases. Free Radic Biol Med 2002; 33;(1.);1-14. | Article | Pubmed

9. Iliakis $G$, Wang $H$, Perrault AR, Boecker W, Rosidi B, Windhofer F, et al.: Mechanisms of DNA double strand break repair and chromosome aberration formation. Cytogenet Genome Res 2004; 104;(1-4.);14-20. | Article I Pubmed

10. Gaymes TJ, North PS, Brady N, Hickson ID, Mufti GJ, Rassool FV: Increased error-prone non homologous DNA end-joining--a proposed mechanism of chromosomal instability in Bloom's syndrome. Oncogene 2002; 21;(16.);2525-33. | Article I Pubmed

11. Frankenberg-Schwager M, Gebauer A, Koppe C, Wolf H, Pralle E, Frankenberg D: Single-strand annealing, conservative homologous recombination, nonhomologous DNA end joining, and the cell cycledependent repair of DNA double-strand breaks induced by sparsely or densely ionizing radiation. Radiat Res 2009; 171;(3.);265-73. | Article I Pubmed

12. Saleh-Gohari N, Helleday T: Conservative homologous recombination preferentially repairs DNA double-strand breaks in the $S$ phase of the cell cycle in human cells. Nucleic Acids Res 2004; 32;(12.);3683-8. | Article | Pubmed Abstract | Pubmed Fulltext

13. Tutt A, Bertwistle D, Valentine J, Gabriel A, Swift S, Ross G, et al.: Mutation in Brca2 stimulates error-prone homology-directed repair of DNA double-strand breaks occurring between repeated sequences. EMBO J 2001; 20;(17.);4704-16. | Article | Pubmed Abstract | Pubmed Full Text

14. Xing J, Zhang Y, Han K, Salem AH, Sen SK, Huff CD, et al.: Mobile elements create structural variation: analysis of a complete human genome. Genome Res 2009; 19;(9.);1516-26. | Article | Pubmed Abstract | Pubmed Fulltext

15. Iliakis G: Backup pathways of NHEJ in cells of higher eukaryotes: cell cycle dependence. Radiother Oncol 2009; 92;(3.);310-5. | Article | Pubmed

16. Audebert M, Salles B, Calsou P: Effect of double-strand break DNA sequence on the PARP-1 NHEJ pathway. Biochem Biophys Res Commun 2008; 369;(3.);982-8. | Article | Pubmed

17. Deng X, Prakash A, Dhar K, Baia GS, Kolar C, Oakley GG, et al.: Human replication protein A-Rad52-single-stranded DNA complex: stoichiometry and evidence for strand transfer regulation by phosphorylation. Biochemistry 2009; 48;(28.);6633-43. | Article | Pubmed Abstract | Pubmed Fulltext

18. Yang YG, Saidi A, Frappart PO, Min W, Barrucand C, Dumon-Jones V, et al.: Conditional deletion of Nbs1 in murine cells reveals its role in branching repair pathways of DNA double-strand breaks. EMBO J 2006; 25;(23.);5527-38. | Article | Pubmed Abstract | Pubmed Fulltext

19. de Jager M, Dronkert ML, Modesti M, Beerens CE, Kanaar R, van Gent DC: DNA-binding and strand-annealing activities of human Mre11: implications for its roles in DNA double-strand break repair pathways. Nucleic Acids Res 2001; 29;(6.);1317-25. | Article | Pubmed Abstract | Pubmed Fulltext

20. Symington LS: Role of RAD52 epistasis group genes in homologous recombination and double-strand break repair. Microbiol Mol Biol Rev 2002; 66;(4.);630-70. | Article | Pubmed Abstract | Pubmed Fulltext

21. Feng $Q$, During L, de Mayolo AA, Lettier G, Lisby M, Erdeniz N, et al.: Rad52 and Rad59 exhibit both overlapping and distinct functions. DNA Repair (Amst) 2007; 6;(1.);27-37. | Article | Pubmed

22. J.P. Lao, S.D. Oh, M. Shinohara, A. Shinohara, N. Hunter, Rad52 promotes postinvasion steps of meiotic double-strand-break repair, Mol Cell. 29 (2008) 517-24. | Article | Pubmed

23. Al-Minawi AZ, Saleh-Gohari N, Helleday T: The ERCC1/XPF endonuclease is required for efficient single-strand annealing and gene conversion in mammalian cells. Nucleic Acids Res 2008; 36;(1.);19. | Article | Pubmed Abstract | Pubmed Fulltext

24. Vannier JB, Depeiges A, White C, Gallego ME: ERCC1/XPF protects short telomeres from homologous recombination in Arabidopsis thaliana. PLoS Genet 2009; 5;(2.);e1000380. | Article | Pubmed Abstract | Pubmed Fulltext

25. Gottlich B, Reichenberger S, Feldmann E, Pfeiffer P: Rejoining of DNA double-strand breaks in vitro by single-strand annealing. Eur J Biochem 1998; 258;(2.);387-95. | Article | Pubmed

26. Tyson JJ, Novak B: Temporal organization of the cell cycle. Curr Biol 2008; 18;(17.);R759-R68. | Article | Pubmed Abstract | Pubmed Fulltext

27. Csikasz-Nagy A: Computational systems biology of the cell cycle. Brief Bioinform 2009; 10;(4.);424-34. | Article | Pubmed

28. Sokhansanj BA, Rodrigue GR, Fitch JP, Wilson DM, 3rd: A quantitative model of human DNA base excision repair. I. Mechanistic insights. Nucleic Acids Res 2002; 30;(8.);1817-25. | Article | Pubmed Abstract | Pubmed Fulltext

29. Sokhansanj BA, Wilson DM, 3rd: Estimating the effect of human base excision repair protein variants on the repair of oxidative DNA base damage. Cancer Epidemiol Biomarkers Prev 2006; 15;(5.);1000-8. | Article | Pubmed

30. Foray N, Fertil B, Alsbeih MG, Badie C, Chavaudra N, Iliakis G, et al.: Dose-rate effect on radiation-induced DNA double-strand breaks in the human fibroblast HF19 cell line. Int J Radiat Biol 1996; 69;(2.);2419. | Pubmed

31. Cucinotta FA, Nikjoo H, O'Neill P, Goodhead DT: Kinetics of DSB rejoining and formation of simple chromosome exchange aberrations. Int J Radiat Biol 2000; 76;(11.);1463-74. I Pubmed

32. Friedland $W$, Jacob $P$, Kundrat $P$ : Mechanistic simulation of radiation damage to DNA and its repair: on the track towards systems radiation biology modelling. Radiat Prot Dosimetry 2011; 143;(2-4.);542-8. | Article I Pubmed

33. Friedland W, Jacob P, Kundrat P: Stochastic simulation of DNA doublestrand break repair by non-homologous end joining based on track structure calculations. Radiat Res 2010; 173;(5.);677-88. | Article | Pubmed

34. Friedland W, Dingfelder M, Kundrat $P$, Jacob P: Track structures, DNA targets and radiation effects in the biophysical Monte Carlo simulation 
Taleei et al. Journal of Molecular Engineering \& Systems Biology 2012, http://www.hoajonline.com/journals/pdf/2050-1412-1-1.pdf

code PARTRAC. Mutat Res 2011; 711;(1-2.);28-40. | Article | Pubmed

35. Taleei $R$, Weinfeld $M$, Nikjoo H: A kinetic model of single-strand annealing for the repair of DNA double-strand breaks. Radiat Prot Dosimetry 2011; 143;(2-4.);191-5. I Article | Pubmed

36. Cucinotta FA, Pluth JM, Anderson JA, Harper JV, O'Neill P: Biochemical kinetics model of DSB repair and induction of gamma-H2AX foci by non-homologous end joining. Radiat Res 2008; 169;(2.);214-22. | Article | Pubmed

37. Mansour WY, Schumacher S, Rosskopf R, Rhein T, Schmidt-Petersen F, Gatzemeier F, et al.: Hierarchy of nonhomologous end-joining, singlestrand annealing and gene conversion at site-directed DNA doublestrand breaks. Nucleic Acids Res 2008; 36;(12.);4088-98. | Article | Pubmed Abstract | Pubmed Fulltext

38. Agmon N, Pur S, Liefshitz B, Kupiec M: Analysis of repair mechanism choice during homologous recombination. Nucleic Acids Res 2009; 37;(15.);5081-92. | Article | Pubmed Abstract | Pubmed Fulltext

39. Barlow JH, Lisby $M$, Rothstein R: Differential regulation of the cellular response to DNA double-strand breaks in G1. Mol Cell 2008; 30;(1.);73-85. | Article | Pubmed Abstract | Pubmed Fulltext

40. Mortensen UH, Bendixen C, Sunjevaric I, Rothstein R: DNA strand annealing is promoted by the yeast Rad52 protein. Proc Natl Acad Sci US A 1996; 93;(20.);10729-34. | Article | Pubmed Abstract | Pubmed Fulltext

41. Sonoda E, Sasaki MS, Buerstedde JM, Bezzubova O, Shinohara A, Ogawa $H$, et al.: Rad51-deficient vertebrate cells accumulate chromosomal breaks prior to cell death. EMBO J 1998; 17;(2.);598-608. | Article | Pubmed Abstract | Pubmed Fulltext

42. Sugiyama T, New JH, Kowalczykowski SC: DNA annealing by RAD52 protein is stimulated by specific interaction with the complex of replication protein A and single-stranded DNA. Proc Natl Acad Sci U S A 1998; 95;(11.);6049-54. | Article | Pubmed Abstract | Pubmed Fulltext

43. Wang H, Zeng ZC, Bui TA, Sonoda E, Takata M, Takeda S, et al.: Efficient rejoining of radiation-induced DNA double-strand breaks in vertebrate cells deficient in genes of the RAD52 epistasis group. Oncogene 2001; 20;(18.);2212-24. | Article | Pubmed

44. Wu W, Wang M, Singh SK, Mussfeldt T, Iliakis G: Repair of radiation induced DNA double strand breaks by backup NHEJ is enhanced in G2. DNA Repair (Amst) 2008; 7;(2.);329-38. | Article | Pubmed

45. Kasten-Pisula U, Menegakis A, Brammer I, Borgmann K, Mansour WY, Degenhardt $S$, et al.: The extreme radiosensitivity of the squamous cell carcinoma SKX is due to a defect in double-strand break repair. Radiother Oncol 2009; 90;(2.);257-64. | Article | Pubmed

46. Sancar A, Lindsey-Boltz LA, Unsal-Kacmaz K, Linn S: Molecular mechanisms of mammalian DNA repair and the DNA damage checkpoints. Annu Rev Biochem 2004; 73;(39-85. | Article I Pubmed

47. Johnson-Schlitz DM, Flores C, Engels WR: Multiple-pathway analysis of double-strand break repair mutations in Drosophila. PLoS Genet 2007; 3;(4.);e50. | Article | Pubmed Abstract | Pubmed Fulltext

48. DiBiase SJ, Zeng ZC, Chen R, Hyslop T, Curran WJ, Jr., Iliakis G: DNAdependent protein kinase stimulates an independently active, nonhomologous, end-joining apparatus. Cancer Res 2000; 60;(5.);1245-53. | Article | Pubmed

\section{Citation:}

Taleei R, Weinfeld M and Nikjoo H: Single strand annealing mathematical model for double strand break repair. journal of Molecular Engineering and Systems Biology 2012, 1:1.

http://dx.doi.org/10.7243/2050-1412-1-1 